\title{
Wind turbines as yet unsuitable as electricity providers
}

^C. le Pair, F. Udo and K. de Groot - DOI: 10.1051/epn/2012204

Wind turbines have been widely accepted as electricity producers thanks to claims that wind comes free of charge, and each $\mathrm{kWh}$ thus produced replaces a $\mathrm{kWh}$ provided by conventional techniques, i.e., it saves the fossil fuel otherwise needed. However, these assumptions have never been validated in existing power distribution systems even after the installation of as much as $86 \mathrm{GW}$ of wind power in Europe alone.

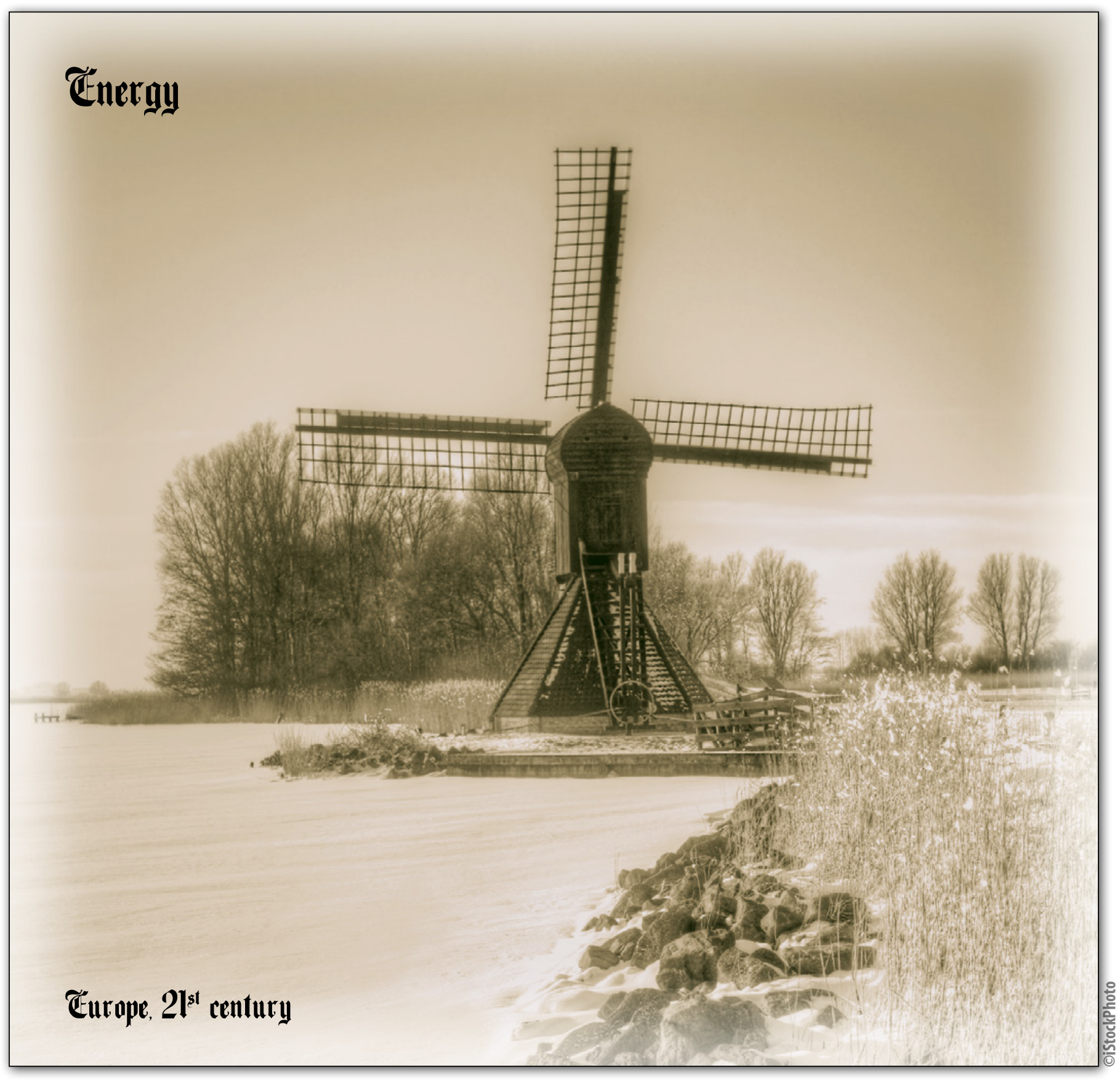


T he wind energy flux varies with the third power of the wind speed. Wind energy is only available if the wind blows strongly enough. This is expressed by saying that wind energy is supply driven: it is not available on demand.

This feature makes wind energy as such unsuitable as a power source for an electricity grid where supply and demand must be balanced at all times. In order to stabilise the power of the grid we need either storage or conventional generators as backup. This has important consequences, as it reduces the fuel savings promised by the wind industry, while it doubles the costs of the power systems.

An often-heard objection to this argument is that by spreading wind turbines over a large area the fluctuations in wind fields average out. This argument can be quantified by looking at the correlation length in wind patterns. Rather than discussing these wind patterns we discuss the production of 7000 wind turbines in Germany.

In 2004 the electricity company E.ON had some $7 \mathrm{GW}$ of wind power installed over the whole territory of Germany. In their 'Wind report 2005' [1] they published the wind electricity produced in 2004 on a day-by-day basis (Fig. 1). The conclusion is that on a 24 hour basis the correlation in wind energy production is strong over all of Germany. This effect has been analysed for the case of Germany by the Aachen University [2]. The result is that the possible substitution of conventional sources by wind is only a few per cent of the installed wind capacity. This result is in contradiction to the statement of Eecen et al. [3]. Other studies have shown a strong correlation between the wind energy production in Denmark, Germany and Great Britain together. The North Sea is often hailed as the futurepowerhouse of Europe, but its opening hours are quite irregular... This implies that wind power is not an alternative for conventional production capacity. The investment in wind turbines requires extra capital on top of the cost of a conventional system, which by itself is already capable to satisfy the total demand. Moreover this extra capacity also requires extra connection lines. In Germany the plans to install more wind turbines require $4000 \mathrm{~km}$ of extra high voltage transmission lines, which otherwise would not be necessary.

\section{The capacity factor and curtaillment}

The frequency distribution of the wind velocity is described by the Weibull distribution, which reveals that wind speeds from zero to the average wind force are as frequent as all other wind speeds together. An average wind speed is typically $6 \mathrm{~m} / \mathrm{s}$ onshore. The average wind force is larger at sea than onshore.

Windmills start producing electricity at about $5 \mathrm{~m} / \mathrm{sec}$ and reach full power at $13 \mathrm{~m} / \mathrm{sec}$. The capacity factor of a wind turbine is the fraction of the time it effectively runs at full capacity. The capacity factors offshore are about 0,4 and about 0,25 in good locations onshore. The measured factors are 0,22 for the Netherlands, 0,17 for Germany and 0,24 for Ireland.

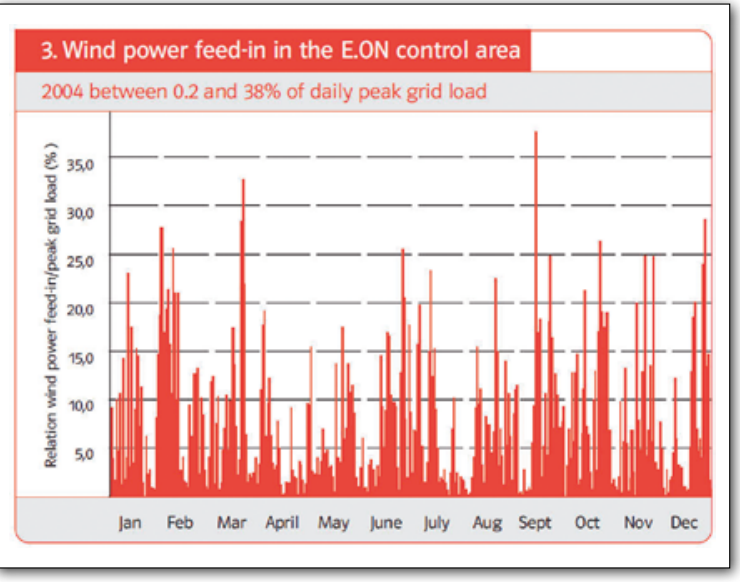

$\varangle$ FIG 1: Daily wind electricity contribution

This means that a wind energy system which has enough capacity to satisfy the demand, covers less than $25 \%$ of the total demand during a year.

\section{Is it possible to absorb such an amount of wind energy} in a conventional system?

Here we follow the calculations done by B. Ummels [4]. The electricity demand follows a curve which is largely the same everywhere in Europe. Figure 2 represents such a curve for the weekly demand in the Netherlands in 2007. Such curves are in use by the producers to balance supply and demand. Taking a full year of such curves, we split the total demand in 15 -minute periods to arrive at $365 \times 24 \times 4=35040$ periods of demand. The computer now sorts the 15 -minute intervals with their demand in decreasing order and puts them on theY-axis of Fig. 3. These points form the top curve in the graph. It shows the so-called demand-duration curve for the Netherlands. One can see that the maximum electricity demand was around $20 \mathrm{GW}$, and the minimum just below $10 \mathrm{GW}$. Next one can obtain the data on wind speed per 15-minute interval from the Meteorological Institute. These data allow calculating the actual wind electricity yields for any desirable total installed capacity. This wind-generated electricity yield (for each relevant 15 minute time slot during the year) can be subtracted from the demand, so the production of wind energy is now represented as a negative demand. Ummels [4] has done this for installed capacities of 2 to 12 GW in 2 GW steps (see Fig. 3).

The 'must run' capacity is defined as the minimum output of a conventional system under the requirement that it can deliver full output on short notice, i.e., during a period of rising demand and falling wind production. The 'must run' output is represented as a horizontal line in figure 3. The height of this line is a subject of debate, but the choice of $10 \mathrm{GW}$ is the result of the following arguments:

A. The difficulty of running large installations below $50 \%$ of full load.

B. Industrial electricity production in combined heat and power installations is beyond control of the electricity distribution network. The same holds for Combined Heat and Power (CHP) installations used for district heating. 
v FIG 2: Typical behaviour of total electricity demand over a period of a week
C. Cycling of coal-fuelled generators can lead to unexpected consequences, as detailed in the Bentek report about the Colorado electricity supply [5]

The surface under the horizontal line represents the amount of wind energy which cannot be accommodated in the grid. With $12 \mathrm{GW}$ wind power installed one could theoretically provide $20 \%$ of the total demand. However, the demand-duration curves demonstrate that about half the time there is surplus wind power. The total surplus amounts to $40 \%$ of the supply by wind. Not only is a solid $40 \%$ of the wind production lost, but also the conventional system has to run at minimum capacity during exactly half the time. Export is still touted as the solution for wind energy oversupply. This argument is not valid because, when we have high winds in one country in Western Europe, it also blows in the surrounding countries. Such is the nature of our weather systems.

Let us turn again to the great example for the wind proponents, i.e., the Danish situation. The Danes produce $20 \%$ of their electricity by wind, but half of that cannot be accommodated locally. This oversupply is exported to Norway and Sweden, where it is used to replace hydro electricity. Since 2010 the Scandinavian Power market rewards electricity oversupply with a negative price of up to $€ 200$ per MWh, or $€ 0,2$ per kWh.

CEPOS, an independent Danish scientific institute, has issued a report entitled: "Wind energy, the case of Denmark" [6]. The authors are quite explicitly negative about the practice of supplying free (subsidized) wind electricity to their Scandinavian neighbours at times of oversupply, and the purchase of electricity at high cost during periods when the wind cannot deliver.

We quote from page 29: "The very fact that the wind power system, that has been imposed so expensively upon the consumers, cannot and does not achieve the simple objectives for which it was built, should be warning the energy establishment, at all levels, of the considerable gap between aspiration and reality." Negative electricity prices are the only way to stop the turbines, but this phenomenon endangers the exploitation of the conventional power generation system, unless the government (i.e., the citizens) pays additional subsidies to keep the backup systems running.

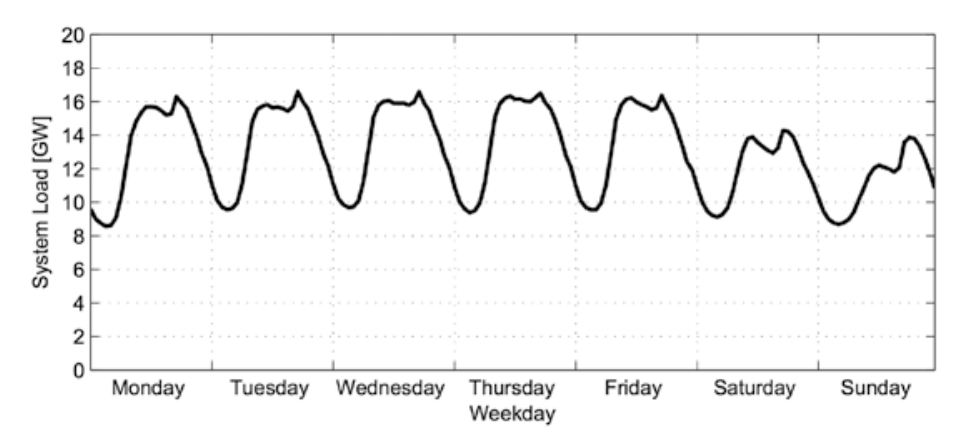

\section{The saving of fossil fuel}

Many studies worldwide indicate that the fuel saved by wind is far less than proponents assume. [7,8,9]. Most of those studies are based on models by lack of operational data with two exceptions: The Bentek report on wind in Colorado and Texas [4] and Udo's analysis of the operational data of EirGrid [10].

But let us first review the factors affecting the actual performance of the electricity-generating system when wind turbines are added.

The widely published argument in favour of wind energy is: "The conventional units produce less energy, so they consume less fuel". Several factors influence this simple result in a negative sense.

1. Conventional units are forced to operate at less than optimal power due to supply of wind electricity. As a consequence, they have a lower thermal efficiency. They consume more fuel per kWh compared to the consumption without wind.

2. Cycling conventional units - ramping up or down - in response to fluctuating wind contribution uses more fuel than running at constant power.

Idling of conventional generators synchronous with the grid but not delivering electric power costs $6-8 \%$ of the fuel required for running at design capacity. This is necessary to step in, at sudden lulls of the wind over wind turbine arrays.

Extra cold starts of conventional units easily require more fuel than wind developments produce. For example: one cold start of a highly efficient $360 \mathrm{MW}$ CCGT (Combined Cycle Gas Turbine) consumes the fuel equivalent to the electric energy which twenty 3 MW wind turbines produce during 40 hours running on average output.

Construction and installation of wind turbines requires a quantity of energy equivalent to about $10 \%$ of their life-time production [11].

6. Capital costs and energy involved in connecting wind turbine parks to the grid, including adaption and transforming, have to be added to the wind park costs and subtracted from yields [12].

Self-consumption of electric energy by wind turbines and their electronics while idling and at rest, i.e., heating during cold periods and electricity consumed by the power electronics for grid adaption [13].

8. Increased use of inefficient, fast ramping OCGTs (Open Cycle GAS Turbines) instead of twice as efficient CCGTs to meet sudden wind variations.

9. Energy costs related to extra wear and tear of conventional units due to frequent forced ramping in response to the wind variations.

The Bentek study used the actual exhaust data of $\mathrm{CO}_{2}$ and other gases before and after the introduction of wind developments. The authors corrected for import 
and export, change in demand and other relevant factors. The conclusion is: wind does not save fuel and does not reduce emissions in Colorado and Texas.

Udo's review of the actual Irish data revealed that a $12 \%$ wind contribution in the Irish grid system without largescale storage resulted in a fuel saving of 5\%. In the Bentek research the factors 5, $6 \& 9$ are not taken into account. The inclusion of 7 is dubious. In the EirGrid data, the basis of Udo's analysis, the factors 4, 5, 6 \& 9 were not taken into account. The inclusion of 3 and 7 is uncertain.

\section{The cost of wind energy}

In the article of Eecen et al. [3] two claims are made about the costs of wind energy:

A. "The cost of onshore wind energy reaches the cost of fossil energy..."

\section{Our comments are the following:}

1. The product of a windmill is supply driven, so it does not have the same value as conventional electricity. Formerly this was partly expressed by the imposition of imbalance costs on the producers of wind energy. These costs are now paid by the consumers. Experts estimate the true value of wind energy between 1 and 3 cents per kWh. [14]

2. The interest rates have been exceptionally low in the last years, while the dominant part of the cost of wind energy is capital. This partly explains the recent decrease in cost of onshore wind energy.

3. The environmental costs are omitted in the price of onshore wind. Land occupation: The distance between turbines of a wind farm must be large due to the wake effects described in ref. [3]. The result is that the capacity density cannot be more than $9 \mathrm{MW} / \mathrm{km}^{2}$, so $9 \mathrm{GW}$ of wind capacity will occupy around $1000 \mathrm{~km}^{2}$ of land area. This territory will be unfit for human occupation because of continuous noise and flicker effects. Lowering of estate values. Surveys have shown that houses within sight of wind parks lose an appreciable percentage of their value. In highly populated areas this depreciation is larger than the amount of capital invested in wind turbines.

B. “...it is expected that the relatively young offshore wind technology will experience a strong learning curve, leading to significant cost reductions"

We note: From 2005 to 2010 the cost of installing offshore wind farms has increased from 2 million euro/MW to 4 million euro/MW [15]. This is a strong learning curve indeed.

\section{Conclusion}

Quantifying the decrease in efficiency of the electric power system and the extra fuel consumption induced by wind developments is by no means a simple matter. To our knowledge there are presently not sufficient data in the public domain to substantiate a definite answer to the question

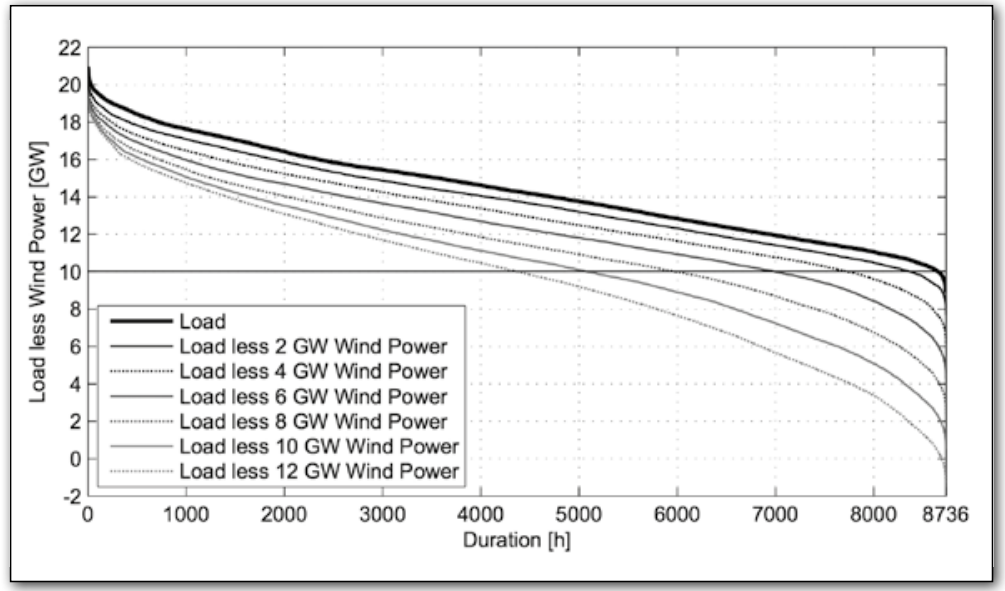

how much fuel and $\mathrm{CO}_{2}$ emission is saved. It depends on the actors, the equipment, the kind of fuel, the amount of wind penetration, the behaviour of the regional wind, the amount of storage, the interconnection of regional grids etc.

Decisions to install large-scale wind-powered electricity generation are based more on the expectation to save significant amounts of fossil fuel and $\mathrm{CO}_{2}$ emission than on any evidence that this is indeed the case.

Wind technology is not suited for large-scale application without a good buffer and storage system. We propose to stop spending public money on large-scale use of wind. This money should be spent on R\&D of future power systems. We expect that wind will not play an important role in these future systems.

\section{References}

[1] E.ON: Wind Report 2005, page 7.

[2] Ibid. page 9.

[3] P. Eecen, H.A. Bijleveld and B. Sanderse in this issue of Europhysics News.

[4] B. Ummels, Thesis, Delft University of Technology, 2009.

[5] "How less became more":Wind, Power and unintended consequences in the Colorado Energy Market, 2010 (www.bentekenergy.com).

[6] CEPOS 2009: www.cepos.dk/english/analyses-and-notes/

[7] Kent Hawkins, MasterResource Nov. 2009 "Wind integration". www.masterresource.org/2009/11/wind-integration-incremental-emissions-from-back-up-generation-cycling-part-i-aframework-and-calculator/

[8] W. Post, The Energy collective: www.theenergycollective.com/willempost/64492/wind-energy-reduces-co2-emissions-few-percent?

[9] W. Boone MasterResource Sept 2010. www.masterresource. org/2010/09/windpower-overblown-part-1/

[10] F. Udo: www.clepair.net/Udo-okt-e.html .

[11] Wind proponents usually claim it is 3 to 6 months. C. le Pair \& K. de Groot: www.clepair.net/windefficiency.html , note 13.

[12] C. le Pair: www.clepair.net/windSchiphol.html , 4b \& 4c.

[13] The British Consumer Society, WHICH, discovered that small wind turbines for individual houses use more electricity than they produce, due to self-consumption of their power electronics.

[14] WalterConsultancy Ir.R.N.Walter - Oosterhout, September 2011.

[15] KEMA-ECF “Power perspectives 2030", full report page 32. $\triangle F I G$ 3:

Demand-duration curves in the power (upper curve) and with the wind power contributions indicated absence of wind 